\title{
Understanding the omnivore, vegetarian, vegan, and paleo dietary patterns: How they differ in disordered eating indicators
}

\author{
Compreendendo diferentes padrões alimentares — Omnívoro, vegetariano, \\ vegano e paleo: Diferenças em indicadores de perturbação alimentar
}

\author{
Maria Coimbra (1) \\ Cláudia Ferreira (1) \\ (1) Univ Coimbra, CINEICC - Center for Research in Neuropsychology and Cognitive Behavioral Intervention, Portugal
}

Received: 08/03/2021; Reviewed: 06/04/2021; Accepted: 03/05/2021.

https://doi.org/10.31211/rpics.2021.7.1.205

Check for updates

\begin{abstract}
Background and Objective: Disordered eating behaviours are a spectrum of maladaptive eating behaviours that affect a substantial proportion of today's society, having been studied regarding their relationship with different dietary patterns. The present study aimed to better characterise the omnivore, vegan, vegetarian and palaeolithic (paleo) dietary patterns and explore dietary pattern's differences regarding disordered eating indicators, sociodemographic data, the motive of choice of dietary pattern and perception of health value. Method: All data were collected online, comprising a sample of 447 [omnivores $(n=281)$, vegetarians $(n=61)$, vegans $(n=50)$ and paleo $(n=55)$ ] women from the general Portuguese population. Results: Results revealed that the dietary patterns differed regarding motive of choice (omnivores: "Family habit"; vegetarians and vegans: "Ethical/Moral"; paleo: "Weight/Shape control") and on the self-assessed health value of their dietary pattern, with the vegan and paleo diets reporting the highest values. Finally, the groups differed significantly regarding disordered eating, binge eating, and orthorexic behaviours, with the paleo group generally presenting the highest values. Conclusions: This study highlights the importance of exploring the individual's dietary pattern, including motive of choice, in the field of eating psychopathology, with an emphasis on the paleo diet as a risk factor. This means that prevention and intervention clinical guidelines should be developed for individuals with this dietary pattern.
\end{abstract}

Keywords: Dietary pattern; Disordered eating behaviours; Binge eating behaviours; Orthorexic behaviours; Paleo diet; Descriptive cross-sectional study.

\section{DI\&D | ISMT}

rpics@ismt.pt https://rpics.ismt.pt
Publicação em Acesso Aberto

(C) 2021. O(s) Autor(es). Este é um artigo de acesso aberto distribuído sob a Licença Creative Commons Attribution, que permite uso, distribuição e reprodução sem restrições em qualquer meio, desde que o trabalho original seja devidamente citado.
Maria Coimbra

R. do Colégio Novo, Apartado 6153

3001-802 Coimbra, Portugal

E-mail: maria.rcoimbra@gmail.com 


\section{Resumo}

Contexto e Objetivo: Comportamentos alimentares perturbados são um espectro de comportamentos alimentares inadequados que afetam uma proporção substancial da sociedade atual, tendo sido estudados quanto à sua relação com diferentes padrões alimentares. O presente estudo teve como objetivo caracterizar melhor os padrões alimentares omnívoro, vegano, vegetariano e paleolítico (paleo), explorando as diferenças entre estes padrões alimentares relativamente aos indicadores de perturbação alimentar, dados sociodemográficos, motivo de escolha de padrão alimentar e perceção de nível de saúde. Métodos: Todos os dados foram recolhidos online, compreendendo uma amostra de 447 [onívoros $(n=281)$, vegetarianos $(n=61)$, veganos $(n=50)$ e paleo $(n=55)$ ] mulheres da população geral portuguesa. Resultados: Os resultados revelaram que os padrões alimentares diferiram quanto ao motivo de escolha (omnívoros: "Hábito familiar"; vegetarianos e veganos: "Ético / Moral”; paleo: "Controle de peso / forma") e quanto ao nível de saúde autoavaliado do seu padrão alimentar, com as dietas vegana e paleo revelando os valores mais elevados. Por fim, os grupos diferiram significativamente em relação aos comportamentos alimentares perturbados, de compulsão alimentar e ortoréticos, com o grupo paleo apresentando os valores mais elevados, na generalidade. Conclusões: Este estudo destaca a importância de explorar o padrão alimentar do indivíduo, incluindo o motivo de escolha, no campo da psicopatologia alimentar, colocando ênfase na dieta paleo enquanto fator de risco. Isso significa que diretrizes clínicas de prevenção e intervenção devem ser desenvolvidas para indivíduos com este padrão alimentar.

Palavras-Chave: Padrão alimentar; Comportamentos alimentares perturbados; Comportamentos de compulsão alimentar; Comportamentos ortoréticos; Dieta Paleo; Estudo transversal descritivo.

\section{Introduction}

In the last few years, the adherence to different dietary patterns has been rising, and though research around these dietary patterns and their role in the field of eating-related psychology is still young, there has been a recent focus around it (Cramer et al. 2017; Paslakis et al., 2020).

The main dietary patterns discussed and subject of investigation are omnivore, vegetarian, and vegan. Overall, the main difference between these three dietary patterns is the consumption of meat and animal products. The omnivore diet is associated with the inclusion of meat and animal products, while the vegan diet is characterised by the complete avoidance of meat and animal products (Heiss et al., 2017a; Paslakis et al., 2020). The vegetarian diet is harder to characterised: while full vegetarians avoid meat and fish completely, there are different types of vegetarian diets, such as pescetarians (inclusion of fish) and ovo-vegetarians (inclusion of eggs) (Heiss et al., 2017a; Timko et al., 2012). Previous research has questioned if different dietary patterns might be associated with more vulnerability for disordered eating behaviours (Brytek-Matera, 2020; Collins \& Quinton, 2020; Timko et al., 2012).

Disordered eating behaviours (DEB) are a spectrum of maladaptive eating behaviours (such as binging, eating restraint, purging, and excessive use of laxatives) that affect a substantial percentage of western society's population (Gauvin et al., 2009; Mitchison et al., 2012). While eating disorders have a prevalence of $0.9 \%$ to 3.5\% in women from western societies (Hudson et al., 2007), DEB have been reported to have a much higher prevalence in women (Ortega-Luyando et al., 2015). Several studies have explored the relationship between meat-avoiding diets (such as vegetarian and vegan) with DEB, but results are inconsistent. Some studies have found higher levels of DEB in meat-avoiding diets when compared with the omnivore diet, with some even suggesting that vegetarian and vegan individuals may adopt such diets in order to "disguise" and justify certain behaviours, serious DEB or even eating disorders (Heiss et al., 2017a; Robinson-O'Brien et al., 2009; Timko et al., 2012). On the contrary, other studies have reported no significant differences between omnivores and meat- 
avoiding diets in their relationship with DEB (Fisak et al., 2006; Forestell et al., 2012; Heiss et al., 2017b). Likewise, meat-avoiding dietary patterns have been studied in regards to their relationship with orthorexic behaviours. Results have also been inconsistent, with some studies reporting a non-significant relationship and some studies finding significant results, when compared to omnivore diets (Çiçekoğlu \& Tunçay, 2018; Ferreira \& Coimbra, 2020; McComb \& Mills, 2018).

Recently, the paleo diet (or palaeolithic diet) has become more popular, with some studies exploring its nutritional and health value as well as associated psychological characteristics or difficulties (Ferreira \& Coimbra, 2020; Klonoff, 2009; Norwood et al., 2019; Pitt, 2006). Despite this, literature concerning paleo's relationship with eating-related difficulties and DEB is still scarce. This diet is often referred to as the caveman diet since it consists of the sole consumption of foods that existed prior to the development of agriculture, excluding (or minimally consuming) grains, cereals, legumes, dairy products, and all processed foods (de la $\mathrm{O}$ et al., 2020; Klonoff, 2009). Contrary to the previously mentioned dietary patterns, the paleo diet is often used as a weight-loss strategy, gaining recognition for its low caloric intake (Obert et al., 2017). This raises the question if the paleo diet is a dietary lifestyle pattern or a weight loss strategy. In contrast, some studies have reported that vegan and vegetarian diets have as a central core the individuals' values and personal beliefs (Ruby, 2012). This indicates that the motive of choice for the individual's diet should be considered when assessing dietary patterns.

So, there is clearly a great need to further explore different dietary patterns - omnivore, vegetarian, vegan, and paleo - and disordered eating behaviours (such as eating restraint, binge eating behaviours, and orthorexic behaviours). At the same time, it is important to better characterise these dietary patterns, specifically on the motive of choice and self-assessed health value, which can play a role in the way they experience their diet and eating behaviour.

We hypothesise that (a) the dietary patterns will differ on their motive of choice, with individuals who identify with the paleo diet using it mainly as a strategy for weight or shape control, (b) there will be significant differences in the self-assessed health value between dietary patterns, with the meat-avoiding diets presenting the highest values, and (c) meat-avoiding diets and the paleo diet will present higher levels of DEB when compared with the omnivore dietary pattern.

\section{Methods}

\section{Participants}

The initial sample was composed of 560 participants from the general Portuguese population, with ages ranging from 15 to 70 years old. After exclusion criteria were applied (excluding (a) male participants, (b) participants younger than 18 years old or older than 65 years old, (c) participants who did not identify with omnivore, vegetarian, vegan, or paleo dietary pattern and (d) participants who selected "Other" for their dietary pattern motive of choice), $20.18 \%$ of the initial sample was excluded.

Therefore, the present study comprised a sample of 447 female participants, with an age range of 18 to 65 years old, from the general Portuguese population. The sample was divided into four groups according to the individual's dietary pattern, omnivores $(n=281)$, vegetarians $(n=61)$, vegans $(n=50)$ and paleo $(n=55)$.

The omnivore group had an age mean of $33.45(S D=11.81)$ and a mean of $14.58(S D=5.54)$ years of education. Concerning the area of residence, $52.3 \%$ of this group resided in an urban area, $22.8 \%$ lived in a semi-urban area, 
and $24.9 \%$ in a rural area. The BMI mean was $24.26(S D=4.54)$, representing a normal BMI according to World Health Organization ([WHO], 2011).

The vegetarian group had an age mean of $31.31(S D=11.34)$ and $14.90(S D=2.63)$ years of education. Sixty-five point six per cent of this group lived in an urban area, $27.9 \%$ in a semi-urban area, and $6.5 \%$ in a rural area. This group also presented a normal BMI ( $M=24.05 ; S D=4.99 ; \mathrm{WHO}, 2011)$.

For the vegan group, the age mean was $30.36(S D=8.89)$, and this group had a mean of $14.94(S D=2.14)$ years of education. In an urban area resided $60 \%$ of this group, $24 \%$ in a semi-urban area, and $16 \%$ in a rural area. The BMI average was $21.25(S D=3.29)$, corresponding to a normal BMI (WHO, 2011).

Finally, the paleo group had an age mean of $41.42(S D=8.24)$ and a mean of $13.80(S D=3.02)$ years of education. Regarding the area of residence, $54.5 \%$ of this group lived in an urban area, $18.2 \%$ in a semi-rural area, and $27.3 \%$ in a rural area. The BMI for this sample corresponded to the pre-obesity category $(M=25.85 ; S D=4.50)$, according to WHO (2011).

\section{Procedures}

This paper is part of a wider research centred around the role of different dietary patterns on eating behaviour. The investigation and data collection respected all ethical and deontological requirements inherent to scientific research in psychology and was approved by the Ethics Committee of the Faculty of Psychology and Educational Sciences of the University of Coimbra. The participants were invited to participate in the study through different online social networks and were informed of the study's voluntary and confidential characteristics before answering the survey and signing an informed consent. The full survey took 15-20 minutes to complete. The study had no missing data since all questions were of mandatory answer.

\section{Measures}

\section{Demographic Data}

Participants were asked to report their demographic information (sex, age, years of education, and area of residence).

\section{Data Concerning Dietary Patterns}

Participants were asked to choose which dietary pattern they identified with: omnivore, vegan, vegetarian, paleo, or other. Additionally, participants were asked to select their motive of choice for the adoption of their dietary pattern, with the options being: Ethical/Moral; Family habit; Weight/Shape control; Medical/Sports indication; Other. Participants also answered the question "How healthy do you believe your dietary pattern is?", ranked from 1 "Very unhealthy" to 5 "Very healthy".

\section{Body Mass Index (BMI)}

BMI was calculated by dividing the self-reported weight by the height squared $\left(\mathrm{kg} / \mathrm{m}^{2}\right)$. 


\section{Binge Eating Scale (BES)}

BES (Duarte et al., 2015; Gormally et al., 1982) is a self-report measure that assesses behavioural, cognitive, and emotional features of binge eating. BES includes 16 items, each with three or four statement options, coded from zero to two or three, with higher values indicating higher severity of binge eating. This measure presents good psychometric properties, with a Cronbach's alpha of .85 in the original study, a Cronbach's alpha of . 88 in the Portuguese version, and .90 in the current one.

\section{Düsseldorf Orthorexie Scale (DOS)}

DOS (Barthels et al., 2015; Ferreira \& Coimbra, 2020) is a self-report measure that assesses orthorexic behaviours. The scale has ten items, measured according to a four-point Likert scale (from 1 = "never" to 4 = "always"). Higher total scores represent higher levels of orthorexia. This scale has presented good psychometric properties in the original study and in the Portuguese version (respectively Cronbach's $\alpha=.84 ; .86$ ), and in the current study (Cronbach's $\alpha=.86$ ).

\section{Eating Disorder Examination Questionnaire (EDE-Q)}

EDE-Q (Fairburn \& Beglin, 1994; Machado et al., 2014) is a self-report questionnaire designed to assess disordered eating attitudes and behaviours that occurred in the last 28 days. The scale includes 36 items, ranked by frequency or severity. EDE-Q has shown good psychometric properties in the original and the Portuguese version (with Cronbach's alpha of .97). In the present study, Cronbach's alpha was .95.

\section{Data Analysis}

All data were analysed using SPSS software version 22 (Chicago, IL) with $p$ values of $<.05$, indicating statistical significance.

Group differences regarding dietary pattern's motives of choice were examined through chi-square tests, and group differences regarding dietary pattern's health value and DEB indicators were conducted with ANOVA procedures, with post-hoc comparisons using the Tukey HSD test.

\section{Results}

\section{Sociodemographic Comparisons}

Sociodemographic characteristics were explored and compared between the groups. The four groups presented significant differences in their demographic characteristics regarding age $\left[F_{(3,443)}=11.414 ; p<.001\right]$ and BMI $\left[F_{(3,443)}=9.484 ; p<.001\right]$. However, no significant differences were found regarding years of education $\left[F_{(3,443)}\right.$ $=0.819 ; p=.484]$ and area of residence $\left[\chi^{2}{ }_{(6)}=12.35 ; p=.055\right]$.

\section{Dietary Pattern's Motives of Choice}

Participants' dietary pattern's motives of choice are presented in Figure 1. In the omnivore group $(n=281)$ the most reported motive of choice was "Family habit", for the paleo group $(n=55)$ the most reported motive of choice was "To control weight/shape", and for the vegetarian $(n=61)$ and vegan group $(n=50)$ the most 
reported motive of choice was "Ethical/Moral". The groups presented significant differences between them $\left[\chi^{2}(9)=290.56 ; p<.001\right]$.

\section{Figure 1}

Dietary Pattern's Motives of Choice Distribution

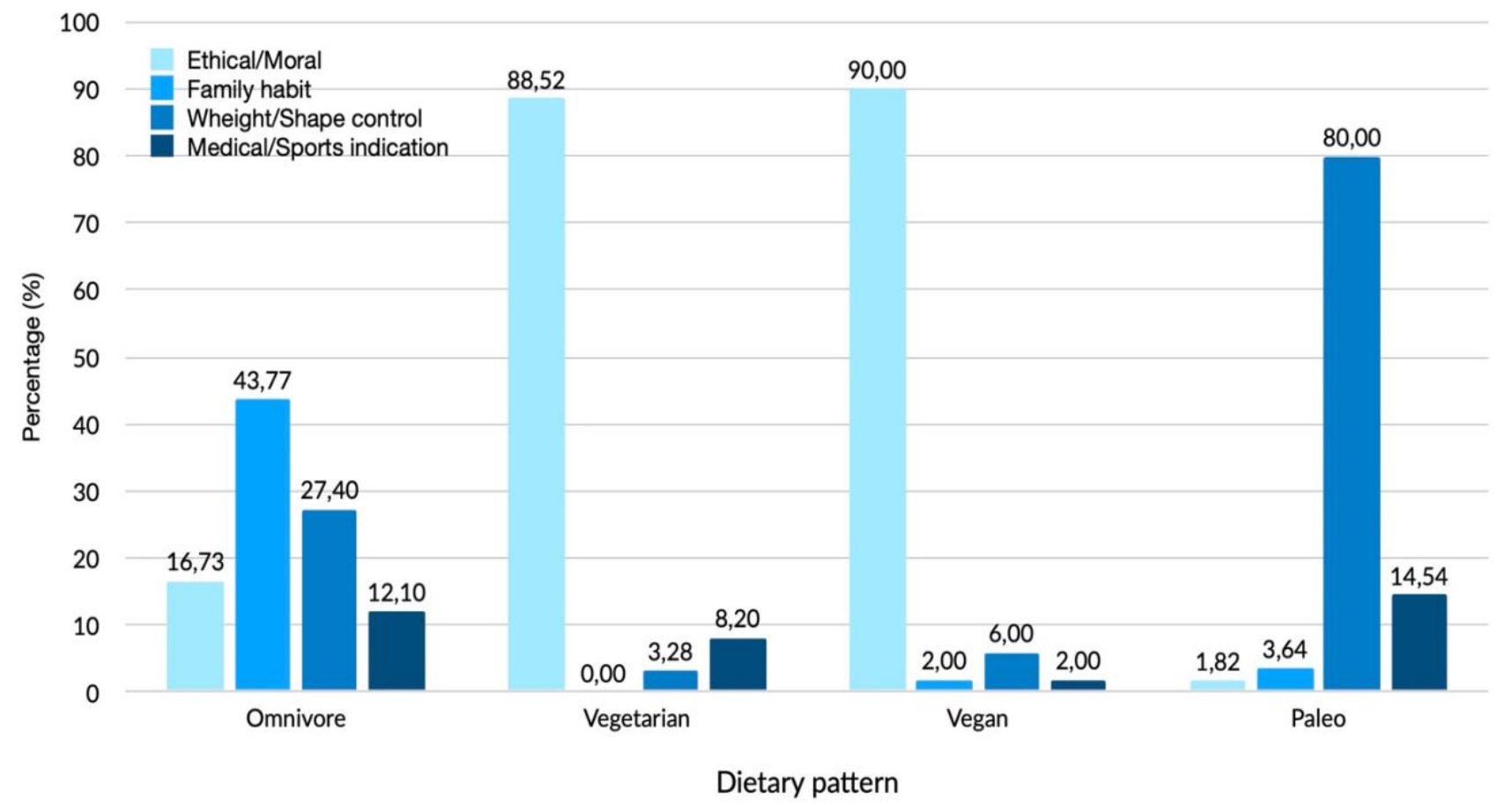

\section{Dietary Pattern Self-Assessed Health Value}

Participants answered the question "How healthy do you believe your dietary pattern is?" as shown in Figure 2. The paleo group presented the highest reported value, and the omnivore group reported the lowest value. The groups presented significant differences between them regarding the reported health value of their dietary pattern $\left[F_{(3,443)}=44.09, p<.001\right]$. Post-hoc comparisons revealed that the omnivore group $(M=3.39, S D=0.75)$ differed from all other groups, the vegetarian group $(M=3.80, S D=0.81)$ also differed from all other groups, while the vegan $(M=4.30, S D=0.54)$ and paleo $(M=4.36, S D=0.62)$ groups only differed from the omnivore and vegetarian groups. 


\section{Figure 2}

Means and Standard Deviations of Self-assessed Health Value by Dietary Pattern

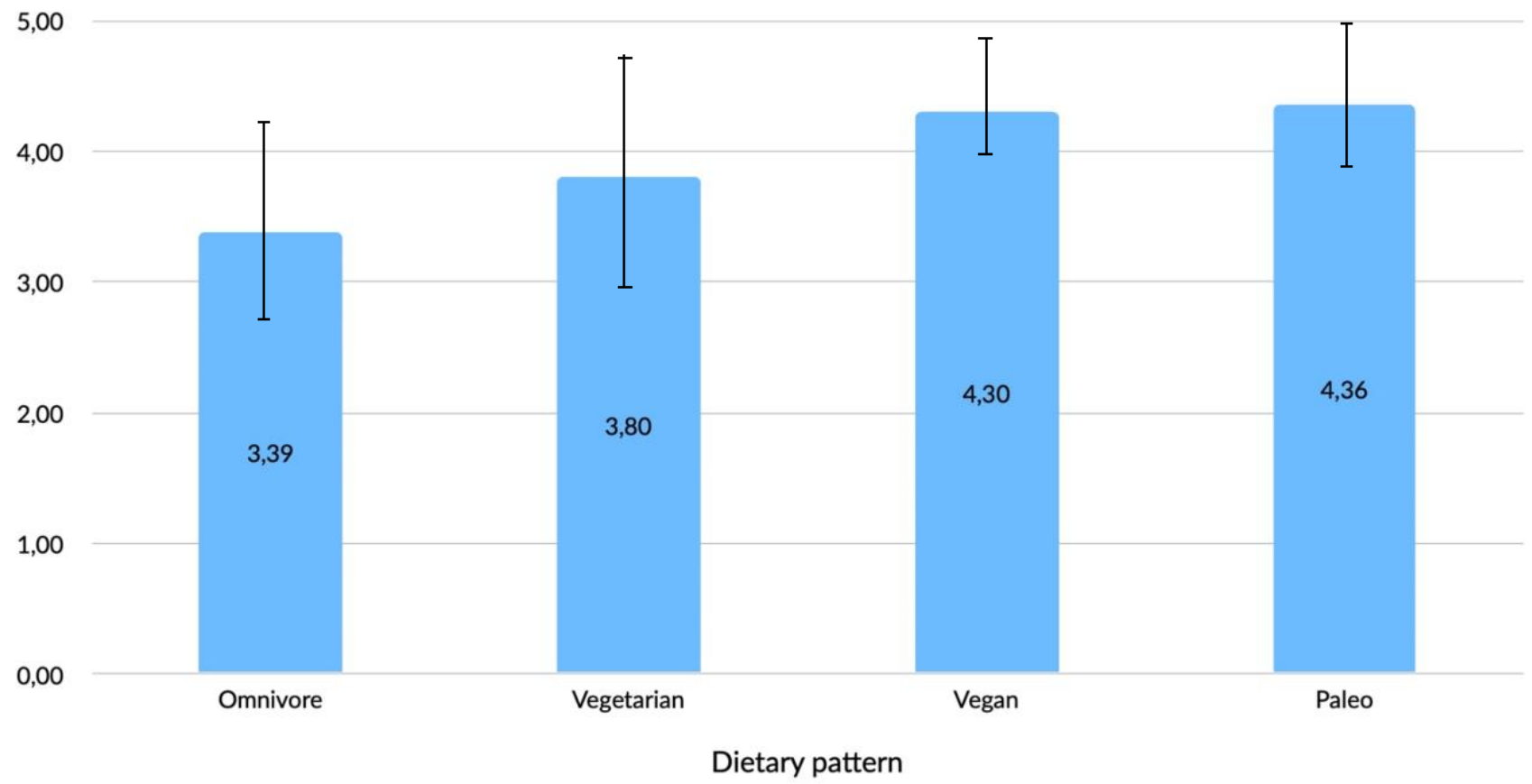

\section{Differences Between Dietary Patterns Regarding Disordered Eating Behaviour Indicators}

Dietary pattern group differences for DEB (EDE-Q, BES, and DOS-P) were explored. Results revealed statistically significant differences regarding EDE-Q, BES, and DOS-P.

Table 1

Comparisons of Disordered Eating Behaviour Indicators by Dietary Pattern

\begin{tabular}{lccccccccccc}
\hline & $\begin{array}{c}\text { Omnivore } \\
(\mathrm{O} ; n=281)\end{array}$ & $\begin{array}{c}\text { Vegetarian } \\
(\mathrm{Vt} ; n=61)\end{array}$ & $\begin{array}{c}\text { Vegan } \\
(\mathrm{V} ; n=50)\end{array}$ & $\begin{array}{c}\text { Paleo } \\
(\mathrm{P} ; n=55)\end{array}$ & & \\
\cline { 2 - 8 } & $M$ & $S D$ & $M$ & $S D$ & $M$ & $S D$ & $M$ & $S D$ & & $p$ & Post-Hoc \\
\hline EDE-Q & 1.21 & 1.17 & 1.32 & 1.24 & 0.94 & 1.16 & 1.80 & 1.25 & $4.81 ; 3$ & .003 & $\mathrm{~V}, \mathrm{O}<\mathrm{P}$ \\
BES & 7.33 & 7.44 & 9.56 & 9.22 & 4.78 & 5.06 & 8.85 & 9.41 & $4.08 ; 3$ & .007 & $\mathrm{~V}<\mathrm{P}, \mathrm{Vt}$ \\
DOS-P & 16.69 & 5.92 & 20.07 & 5.38 & 21.76 & 7.35 & 21.91 & 5.99 & $20.45 ; 3$ & $<.001$ & $\mathrm{O}<\mathrm{Vt}, \mathrm{V}, \mathrm{P}$ \\
\hline
\end{tabular}

Note. $N=$ 447. EDE-Q = Eating Disorder Examination Questionnaire; BES = Binge Eating Scale; DOS-P = Dusseldorf Orthorexie Scale - Portuguese version. 


\section{Discussion}

Eating behaviour-related research has explored the role that different dietary patterns might have in disordered eating (Cramer et al. 2017; Paslakis et al., 2020). Recent studies have attempted to include other dietary patterns that are becoming more prevalent in Western societies, as is the case of the paleo diet (Ferreira \& Coimbra, 2020; Klonoff, 2009; Norwood et al., 2019). Therefore, this research has focused on the comparisons and differences between meat-avoiding diets (such as vegan and vegetarian), the omnivore diet, and the paleo diet.

The present study aimed at exploring the group differences between dietary patterns (omnivore, vegetarian, vegan, and paleo) in regards to disordered eating indicators, such as disordered eating (EDE-Q), binge eating (BES) and orthorexic behaviours (DOS-P), while also exploring the self-characterisation of the individuals adopting these dietary patterns, including the motive of choice and perception of health value.

The four groups presented significant differences regarding their age and BMI, with the paleo group presenting the highest values for both sociodemographic characteristics and the vegan group the lowest. These results may be directly related, with higher age possibly explaining higher BMI. However, the higher BMI in the paleo group, placing it in the pre-obesity range, may also be related to the motive of choice this group mainly presents for the adoption of their diet.

Dietary pattern's motives of choice were explored, with results finding that the omnivore group is the most heterogeneous group, with the most common motive being Family habit (43.8\%). The present study's results also clarify that the vegetarian and vegan groups mainly adopt such diets for Ethical/Moral reasons, which aligns with research that associates these dietary patterns' adoption with personal beliefs and values (Ruby, 2012). On the other hand, $80 \%$ of the paleo group admits to adopting this diet to Control weight/shape, which aligns with research that has studied the paleo diet as a weight-loss strategy (Obert et al., 2017). These results confirm our first hypothesis and shed light on the staggering differences between the motive of choice behind the adoption of these dietary patterns.

To further understand how individuals self-assess their diets' health value, participants ranked how healthy they believed their diet to be. Significant differences were found between the four groups, with the omnivore group reporting the lowest value and the vegan and paleo group the highest. Thus, our initial hypothesis was not confirmed since the meat-avoiding diets (vegetarian and vegan) did not both present the highest values, but the vegan and paleo diet did. It is interesting to see that the only group that does not present a normal BMI but instead places in the pre-obesity range, and also acknowledges the adoption of this dietary pattern as a weight/shape control strategy, considers their diet to have the highest health value.

The main aim of the current study was to explore how the dietary patterns differ in DEB, and results revealed significant differences. Regarding disordered eating (assessed by EDE-Q), the paleo group presented significantly higher values than the vegan and omnivore group. It is interesting to note that, like several previous studies (Forestell et al., 2012; Heiss et al., 2017b) but unlike others (Heiss et al., 2017a; Timko et al., 2012), the omnivore group and the meat-avoiding groups (vegan and vegetarian) did not present significant differences in disordered eating. However, when it comes to binge eating behaviours, the vegetarian and paleo group presented significantly higher values when compared with the vegan group. This result suggests that even though the vegetarian and vegan groups are often studied in the same category (meat-avoiding diets), they present significant differences, particularly in binge eating behaviours, and should be considered two distinct groups and patterns. 
Finally, concerning orthorexic behaviours, all groups presented significantly higher values when compared with the omnivore group, which adds to the existing inconsistent results on the matter (McComb \& Mills, 2018). Overall, our hypothesis was confirmed, with the omnivore diet always placing in the lower range when compared with the other groups.

When reflecting on the broader view of these results, the paleo group raises great concerns and presents itself as a completely different dietary pattern (higher BMI, mainly used for weight/shape control, significantly higher values in DEB indicators), which might indicate that this group presents greater vulnerability for the development of eating disorders and other related difficulties. Additionally, the previously mentioned findings suggest that the motive of choice behind the adoption of different dietary patterns may impact the way the individual experiences it, particularly when this motive is Weight/shape control.

\section{Limitations}

Some limitations have to be considered. Firstly, this is an exploratory study, from which it is not possible to draw causal conclusions. However, this study seems to provide interesting and innovative data that could help guide future research in this field. Though DEB have been reported to have a much greater prevalence in women, future studies should include men in their overall samples, making it a better representation of the total Portuguese population. The study sample collection was fully conducted online, which may be associated with certain biases. Moreover, all measures were self-reported, so future studies should include different methodology, for example, clinical interviews.

\section{Conclusion}

Concluding, the present study confirms the importance of exploring eating-related behaviours by dietary group and opens the door for future studies to consider the individual's motive of choice for the adoption of different dietary patterns and the prevention of the development of eating disorders. Moreover, it suggests that the paleo group may represent a particularly vulnerable group for the development of eating-related difficulties. This highlights the importance of future research on this matter, as well as on the development of specific clinical support guidelines for individuals with this dietary pattern, both in cases of prevention and intervention.

Ethical approval | Aprovação Ética: This study was approved by the Ethical Board of the Faculty of Psychology and Educational Sciences of the University of Coimbra. All participants included signed an informed consent. | Este estudo foi aprovado pelo Conselho de Ética da Faculdade de Psicologia e Ciências da Educação da Universidade de Coimbra. Todos os participantes assinaram um consentimento informado.

Conflict of interest | Conflito de interesses: The authors declare no conflict of interest. | Os autores declaram não haver conflito de interesses.

Funding sources | Fontes de financiamento: This research did not receive any specific grant from funding agencies in the public, commercial, or not-for-profit sectors. | Esta investigação não recebeu qualquer subvenção específica de agências de financiamento nos sectores público, comercial, ou sem fins lucrativos.

Availability of data and material: The data collected and used in the present paper may be available upon request. The data is not available since it is still being used as part of a wider research regarding Orthorexia Nervosa. I Os dados recolhidos e utilizados no presente artigo poderão ser disponibilizados mediante pedido. Os dados não estão disponíveis uma vez que ainda estão a ser utilizados como parte de uma investigação mais ampla sobre a Ortorexia Nervosa. 
Contributes: MC: Literature review; Data collection, input, and processing; Manuscript writing. CF: Data collection; Contribution in writing the manuscript; Revision of the final draft of the manuscript. | MC: Revisão da literatura; Recolha, entrada e processamento de dados; Redação do manuscrito. CF: Recolha de dados; Contribuição na redação do manuscrito; Revisão da versão final do manuscrito.

\section{References}

Barthels, F., Meyer, F., \& Pietrowsky, R. (2015). Die düsseldorfer orthorexie skala-konstruktion und evaluation eines fragebogens zur erfassung ortho-rektischen ernährungsverhaltens. Zeitschrift für Klinische Psychologie und Psychotherapie, 44(2), 97-105. https://doi.org/gbxr

Brytek-Matera, A. (2020). Restrained eating and vegan, vegetarian and omnivore dietary intakes. Nutrients, $12(7), 2133$. https://doi.org/gbxs

Collins, M., \& Quinton, S. (2020). The inter-relationship between diet, selflessness, and disordered eating in Australian women. Brain and Behavior, 10(9), Article e01774. https://doi.org/gbxt

Cramer, H., Kessler, C. S., Sundberg, T., Leach, M. J., Schumann, D., Adams, J., \& Lauche, R. (2017). Characteristics of Americans choosing vegetarian and vegan diets for health reasons. Journal of Nutrition Education and Behavior, 49(7), 561-567. https://doi.org/gbx4xr

Çiçekoğlu, P., \& Tunçay, G. Y. (2018). A comparison of eating attitudes between vegans/vegetarians and nonvegans/nonvegetarians in terms of orthorexia nervosa. Archives of Psychiatric Nursing, 32(2), $200-205$. https://doi.org/gdct4r

de la O, V., Zazpe, I., Martínez, J. A., Santiago, S., Carlos, S., Zulet, M. Á., \& Ruiz-Canela, M. (2020). Scoping review of Paleolithic dietary patterns: A definition proposal. Nutrition Research Reviews, 1-29. Advance online publication. https://doi.org/gbxv

Duarte, C., Pinto-Gouveia, J., \& Ferreira, C. (2015). Expanding binge eating assessment: Validity and screening value of the Binge Eating Scale in women from the general population. Eating Behaviors, 18, 41-47. https://doi.org/f7jpxd

Fairburn, C., \& Beglin, S. (1994). Assessment of eating disorders: interview of self-report questionnaire? International Journal of Eating Disorders 16(4), 363-370. https://doi.org/10.1002/1098-108X(199412)

Ferreira, C., \& Coimbra, M. (2020). To further understand orthorexia nervosa: DOS validity for the Portuguese population and its relationship with psychological indicators, sex, BMI and dietary pattern. Eating and Weight Disorders - Studies on Anorexia, Bulimia and Obesity. Advance online publication. https://doi.org/gbxx

Fisak, B., Peterson, R. D., Tantleff-Dunn, S., \& Molnar, J. M. (2006) Challenging previous conceptions of vegetarianism and eating disorders. Eating and Weight Disorders, 11, 195-200. https://doi.org/gbxz

Forestell, C. A., Spaeth, A. M., \& Kane, S. A. (2012). To eat or not to eat red meat. A closer look at the relationship between restrained eating and vegetarianism in college females. Appetite, 58(1), 319-325. https://doi.org/ddz7d9

Gauvin, L., Steiger, H., \& Brodeur, J. (2009). Eating-disorder symptoms and syndromes in a sample of urban-dwelling Canadian women: Contributions toward a population health perspective. International Journal of Eating Disorders, 42(2), 158-165. https://doi.org/d3×5rq

Gormally, J., Black, S., Daston, S., \& Rardin, D. (1982). The assessment of binge eating severity among obese persons. Addictive Behaviors, 7(1), 47-55. https://doi.org/b29mxz

Heiss, S., Coffino, J. A., \& Hormes, J. M. (2017a). Eating and health behaviors in vegans compared to omnivores: Dispelling common myths. Appetite, 118, 129-135. https://doi.org/10.1016/j.appet.2017.08.001

Heiss, S., Hormes, J. M., \& Timko, C. A. (2017b). Vegetarianism and Eating Disorders. Vegetarian and Plant-Based Diets in Health and Disease Prevention, 51-69. https://doi.org/10.1016/b978-0-12-803968-7.00004-6

Hudson, J. I., Hiripi, E., Pope, H. G., \& Kessler, R. C. (2007). The prevalence and correlates of eating disorders in the National Comorbidity Survey Replication. Biological Psychiatry, 61(3), 348-358. https://doi.org/ccds66

Klonoff D. C. (2009). The beneficial effects of a Paleolithic diet on type 2 diabetes and other risk factors for cardiovascular disease. Journal of Diabetes Science and Technology, 3(6), 1229-1232. https://doi.org/gbx3 
Machado, P. P., Martins, C., Vaz, A. R., Conceição, E., Bastos, A. P., \& Gonçalves, S. (2014). Eating disorder examination questionnaire: Psychometric properties and norms for the Portuguese population. European Eating Disorders Review, 22(6), 448-453. https://doi.org/ggxjr3

McComb, S. E., \& Mills, J. S. (2019). Orthorexia nervosa: A review of psychosocial risk factors. Appetite, 140, 50-75. https://doi.org/gf25ph

Mitchison, D., Hay, P., Slewa-Younan, S., \& Mond, J. (2012). Time trends in population prevalence of eating disorder behaviors and their relationship to quality of life. PLOS ONE, 7(11), Article e48450. https://doi.org/gbx4

Norwood, R., Cruwys, T., Chachay, V. S., \& Sheffield, J. (2019). The psychological characteristics of people consuming vegetarian, vegan, paleo, gluten free and weight loss dietary patterns. Obesity Science \& Practice, 5(2), $148-158$. https://doi.org/gbx5

Obert, J., Pearlman, M., Obert, L., \& Chapin, S. (2017). Popular weight loss strategies: A review of four weight loss techniques. Current Gastroenterology Reports, 19, Article 61. https://doi.org/ggkf9t

Ortega-Luyando, M., Alvarez-Rayón, G., Garner, D. M., Amaya-Hernández, A., Bautista-Díaz, M. L., \& Mancilla-Díaz, J. M. (2015). Systematic review of disordered eating behaviors: Methodological considerations for epidemiological research. Revista Mexicana De Trastornos Alimentarios, 6(1), 51-63. https://doi.org/f3g66h

Paslakis, G., Richardson, C., Nöhre, M., Brähler, E., Holzapfel, C., Hilbert, A., \& Zwaan, M. D. (2020). Prevalence and psychopathology of vegetarians and vegans - Results from a representative survey in Germany. Scientific Reports, 10(1), Article 6840. https://doi.org/gbx6

Pitt, C. E. (2016). Cutting through the Paleo hype: The evidence for the Palaeolithic diet. Australian Family Physician, 45(1), 35-38. https://bit.ly/33wdVFb

Robinson-O'Brien, R., Perry, C. L., Wall, M. M., Story, M., \& Neumark-Sztainer, D. (2009). Adolescent and young adult vegetarianism: Better dietary intake and weight outcomes but increased risk of disordered eating behaviors. Journal of the American Dietetic Association, 109(4), 648-655. https://doi.org/fqvgpn

Ruby, M. B. (2012). Vegetarianism. A blossoming field of study. Appetite, 58(1), 141-150. https://doi.org/dtbfzk

Timko, C. A., Hormes, J. M., \& Chubski, J. (2012). Will the real vegetarian please stand up? An investigation of dietary restraint and eating disorder symptoms in vegetarians versus non-vegetarians. Appetite, 58(3), 982-990. https://doi.org/f3w3fj

World Health Organization. (2011). World health statistics. https://bit.ly/3uzUrel 